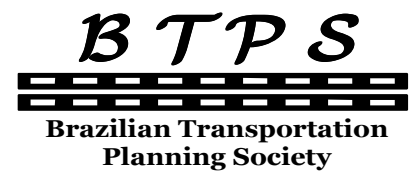
Journal of Transport Literature
Vol. 8, n. 3, pp. 199-228, Jul. 2014
Research Directory

JTL|RELIT

www.transport-literature.org ISSN 2238-1031

\title{
Geração de viagens em estacionamentos: o caso do centro de Niterói
}

[Trip generation in parking lots: the case of downtown Niterói, Brazil]

\author{
Elisabeth Poubel Grieco*, Sergio Marcolini, Osmar Soares Fillho, Licinio da Silva Portugal \\ Rio de Janeiro Federal University - Brazil
}

Submitted 6 May 2013; received in revised form 30 Sep 2013; accepted 1 Nov 2013

\begin{abstract}
Resumo
Este artigo pretende estabelecer equações e taxas de geração de viagens em estacionamentos localizados em áreas centrais, com base na metodologia tradicional adotada pelo Institute of Transportation Engineers - ITE, a partir dos dados levantados em 29 estabelecimentos privados de uso público existentes no centro da cidade de Niterói-RJ. Os resultados encontrados se mostraram consistentes de acordo com as estatísticas encontradas e os parâmetros exigidos na bibliografia. Além disto, foram estabelecidas relações entre as taxas de geração de viagens e variáveis que poderiam influenciá-la, como: o percentual de vagas rotativas; o tempo médio de permanência; o preço; a taxa de ocupação média e o porte dos estacionamentos. Tais resultados contribuem para a concepção de políticas de estacionamento mais adequadas e compatíveis com uma mobilidade orientada às modalidades menos agressivas ambientalmente sem prejudicar a vitalidade das atividades socioeconômicas desenvolvidas na área central.
\end{abstract}

Palavras-Chave: estacionamento, geração de viagens, estacionamentos em área centrais, taxas de geração de viagens.

\section{Abstract}

The aim of this article is to establish trip generation equations and rates based on usage of parking lots located in central city areas, based on the traditional method adopted by the Institute of Transportation Engineers (ITE), employing data gathered at 29 private parking facilities open to the public in downtown Niterói, Rio de Janeiro state, Brazil. The results found are consistent with the statistics found and the parameters established in the relevant literature. Besides this, we established relations between the trip generation rates and variable those influence them, such as percentage of rotating spaces, average parking time and parking facility size. These results contribute to the formulation of parking policies that are more adequate and compatible with transportation modalities that are less environmentally aggressive without impairing the vitality of the socioeconomic activities in downtown areas.

Key words: parking, trip generation, downtown parking facilities, trip generation rates.

*Email: bethgrieco@hotmail.com.

\section{Recommended Citation}

Grieco, E. P., Marcolini, S., Soares Filho, O. and Portugal, L. S. (2014) Geração de viagens em estacionamentos: o caso do centro de Niterói. Journal of Transport Literature, vol. 8, n. 3, pp. 199-228.

- JTL/RELIT is a fully electronic, peer-reviewed, open access, international journal focused on emerging transport markets and published by BPTS - Brazilian Transport Planning Society. Website www.transport-literature.org. ISSN 2238-1031.

This paper is downloadable at www.transport-literature.org/open-access. 


\section{Introdução}

A área central de uma cidade se caracteriza por gerar um grande contingente de viagens que requer uma infraestrutura viária e de transporte com uma capacidade nem sempre disponível, o que exige que ela seja alocada, prioritariamente, para as modalidades de maior produtividade social, como a caminhada, a bicicleta e o transporte público. Por outro lado, se as políticas de restrição ao uso do automóvel se tornam cada vez mais justificadas, nesse contexto potencialmente crítico e com o espaço urbano altamente escasso para atender as distintas demandas, elas se tornam essenciais.

$\mathrm{Na}$ medida em que o estacionamento faz parte de todas as viagens de automóveis, as facilidades e custos a ele associados refletem na propensão de se utilizar essa modalidade individual e na própria divisão modal. Entende-se que a localização, a quantidade e o tipo de controle das vagas de estacionamentos podem interferir na facilidade de atingir destinos, afetando a acessibilidade geral, com impactos positivos e negativos no desenvolvimento da região. Determinar o nível de restrição a ser aplicado considera, portanto, não só a qualidade ambiental e da mobilidade, mas também as condições de acesso que garantam a viabilidade econômica das atividades socioeconômicas presentes na área central (Portugal, 1990; FDOT, 2012).

De acordo com a lógica tradicional, o problema do estacionamento é visto como uma questão de oferta insuficiente para atender à demanda e sua solução passa pela criação de novas vagas, por meio de edifícios garagem ou estacionamentos subterrâneos e de legislação que exige um número mínimo de vagas para novas edificações. Essa lógica considera que a grande oferta de estacionamentos gratuitos ou a um preço baixo é condição necessária para o desenvolvimento das atividades econômicas, particularmente para o comércio (FDOT, 2012).

Os projetos de Shopping Centers seguem esta abordagem baseada no princípio "no parking; no business" e incorporam aos empreendimentos grandes áreas destinadas a estacionamentos. A legislação da maioria das cidades brasileiras também é baseada em tal lógica e estabelece a obrigatoriedade de número mínimo de vagas, geralmente proporcional à área bruta locável ou à área computável dos empreendimentos comerciais. A cidade de Niterói, objeto deste estudo, não constitui uma exceção (Niterói, 1995). 
Numa visão oposta à abordagem tradicional, as políticas orientadas para o gerenciamento da demanda partem do princípio de que a oferta abundante de estacionamento nas áreas centrais tem impacto negativo sobre o trânsito ao incentivarem o uso do automóvel, o que intensifica os congestionamentos, reduzindo o acesso a elas e as suas atividades socioeconômicas (EngelYan, 2010).

Essas políticas podem envolver apenas mecanismos de preço, quando se busca regular a demanda pelo aumento do custo do estacionamento, ou podem ser abrangentes, adotando, além das medidas econômicas, medidas regulatórias, novo desenho urbano e utilização de tecnologia avançada para o controle, fiscalização e informação aos usuários (Kodransky, 2011).

Relatório produzido pelo ITDP - Institute of Transportation and Development Policy (Weinberger, 2010) considera que algumas práticas podem ser adotadas nas áreas centrais, tais como:

- Eliminar a legislação de vagas mínimas e fomentar a venda de unidades desvinculadas das vagas de estacionamento;

- Coordenar os estacionamentos das vias públicas com os particulares;

- Cobrar o estacionamento nas ruas para estimular a rotatividade;

- Criar um fundo para subsidiar ações de melhoria para a comunidade com os recursos arrecadados nos estacionamentos;

- Usar tecnologias disponíveis para oferecer aos consumidores facilidades de pagamento e controle;

- Usar o espaço público destinado aos estacionamentos para outros usos de interesse público;

- Incorporar a gerência dos estacionamentos às políticas de transporte de alta capacidade;

- Criar legislação que limite as emissões de gases de efeito estufa e assegurar a continuidade dos programas;

- Promover programas de incentivo a escolha modal orientada ao transporte público e o não motorizado. 
A determinação da quantidade de vagas a serem oferecidas nas áreas centrais das cidades é um elemento essencial para a formulação de uma política de estacionamento, tanto na abordagem tradicional quanto na baseada no gerenciamento da demanda (Shatinawi, 2010).

A experiência europeia tem mostrado que a redução do uso do automóvel não compromete a vitalidade dos centros urbanos, mas, ao contrário, melhora a qualidade ambiental das cidades, induzindo a comportamentos e hábitos sustentáveis. O espaço ocupado por automóveis nas vias públicas tem sido destinado a vias exclusivas para o transporte público ou mesmo para áreas verdes ou de lazer (Kodransky, 2011). No entanto, as políticas de restrições necessitam de condições que sustentem seu sucesso, como, por exemplo, estarem associadas ao incremento da fiscalização, por conta do risco da ampliação do estacionamento irregular, e à melhoria e ampliação dos transportes públicos (Gonçalves et al., 2012).

Independentemente deste nível de restrição, a politica de estacionamento a ser adotada para ter sucesso pressupõe entender devidamente a geração de viagens de automóveis que o estacionamento proporciona.

Alguns estudos se preocuparam em investigar as necessidades de estacionamento, seja em atividades isoladas, como shopping centers, hipermercados e hospitais (Homburger et al., 2007), seja em áreas centrais de forma agregada, as considerando como um grande Polo Gerador de Viagens - PGVs (Gonçalves et al., 2012). Outros se preocuparam com a geração de viagens especificamente para instalações de estacionamentos considerados como PGVs (ITE, 2004; ITE, 2012). Mas não se identificaram pesquisas sobre modelos e taxas de geração de viagens de automóveis em instalações de estacionamentos em áreas centrais de cidades brasileiras.

Nesse sentido, o presente artigo pretende desenvolver tais modelos e taxas de geração de viagens, a partir de 29 instalações de estacionamentos situadas na área central do Município de Niterói, RJ. Além disso, busca entender a relação entre tal geração de viagens e respectivas taxas com algumas características do uso e ocupação do solo das subáreas em que eles se localizam, bem como com variáveis associadas ao tamanho, tipo (quanto à rotatividade), controle (preço) e uso (tempo de permanência e ocupação) do estacionamento. 


\section{Caracterização do estacionamento}

O desempenho dos sistemas viário, de transporte e mesmo socioeconômico de uma região é fortemente influenciado pelas condições que envolvem o estacionamento (Habib et al., 2012). Sabe-se que o tamanho e o tipo de oferta de estacionamento têm um impacto potencialmente significativo na atratividade do automóvel, com efeito na divisão modal. No entanto, a mobilidade com base no automóvel implica na necessidade de disponibilizar cada vez mais vagas de estacionamento (Seco et al., 2008), ocupando um espaço que poderia ser alocado para outra finalidade, como na ampliação da capacidade viária destinada aos pedestres e ciclistas (Brinco, 2006).

Essa situação torna-se ainda mais crítica na área central de uma cidade, que se caracteriza normalmente por apresentar uma elevada concentração de demanda de viagens, com a malha viária e as instalações de estacionamento saturadas de veículos. Em tal contexto, a procura por vagas acaba gerando o fenômeno do cruising, que é caracterizado pela circulação de veículos em busca de vagas, o que aumenta o tempo da viagem e a circulação de veículos, gerando maior congestionamento no trânsito (Pierce e Shoup, 2013). Estudo realizado na América do Norte propõe um modelo que integra o congestionamento do trânsito provocado por crusing com a gestão dos estacionamentos, buscando o equilíbrio entre a oferta e a procura por meio de adequada política de preços (Arnott et al., 2005).

Segundo Stover e Koepke (2006), os estacionamentos nas áreas centrais das cidades podem ser de diferentes tipos, como: na via ou fora da via; gratuitos ou pagos; públicos ou privados; abertos ao público ou cativos, exclusivos aos proprietários ou arrendatários; rotativos ou não rotativos. Os estacionamentos públicos geralmente são na rua, ao longo do meio fio, ou em terrenos públicos; podem ser rotativos ou não; gratuitos ou pagos, mas, neste caso, de modo geral, tem preços controlados e abaixo do mercado, mesmo quando explorados por empresas privadas em regime de concessão. Geralmente são abertos ao público, mas, em alguns casos, são reservados a autoridades ou servidores de instituições públicas ou, ainda, a veículos de serviço. A resolução do 302/08 do CONTRAN estabelece que as vagas em logradouro público só podem ser reservadas para serviços essenciais, como ambulâncias, carros da polícia e corpo de bombeiros (Denatran, 2008), entretanto ela não é respeitada na maioria das cidades brasileiras. 
Quando se trata de estacionamentos privados, observa-se que existem três tipos (TRB, 2003):

- Aqueles voltados para exploração comercial, que são pagos ao preço do mercado, que podem ser rotativos, quando são abertos ao público em geral e o pagamento é cobrado por hora ou fração; ou mensalistas, quando são reservados aos arrendatários e o pagamento é cobrado por mês;

- Aqueles que são integrados a algum estabelecimento comercial, como os estacionamentos de Shoppings e de Supermercados. Alguns são pagos e rotativos e outros são gratuitos, dependendo da política adotada pelo empreendimento comercial;

- Aqueles cujas vagas são privativas de seus proprietários e são característicos das edificações em que a legislação exige uma vaga para cada sala ou loja comercial.

Este estudo será restrito aos estacionamentos privados voltados para exploração comercial. A Figura 1 mostra a dinâmica dos estacionamentos nas áreas centrais e os fatores que influem na demanda e na oferta por vagas.

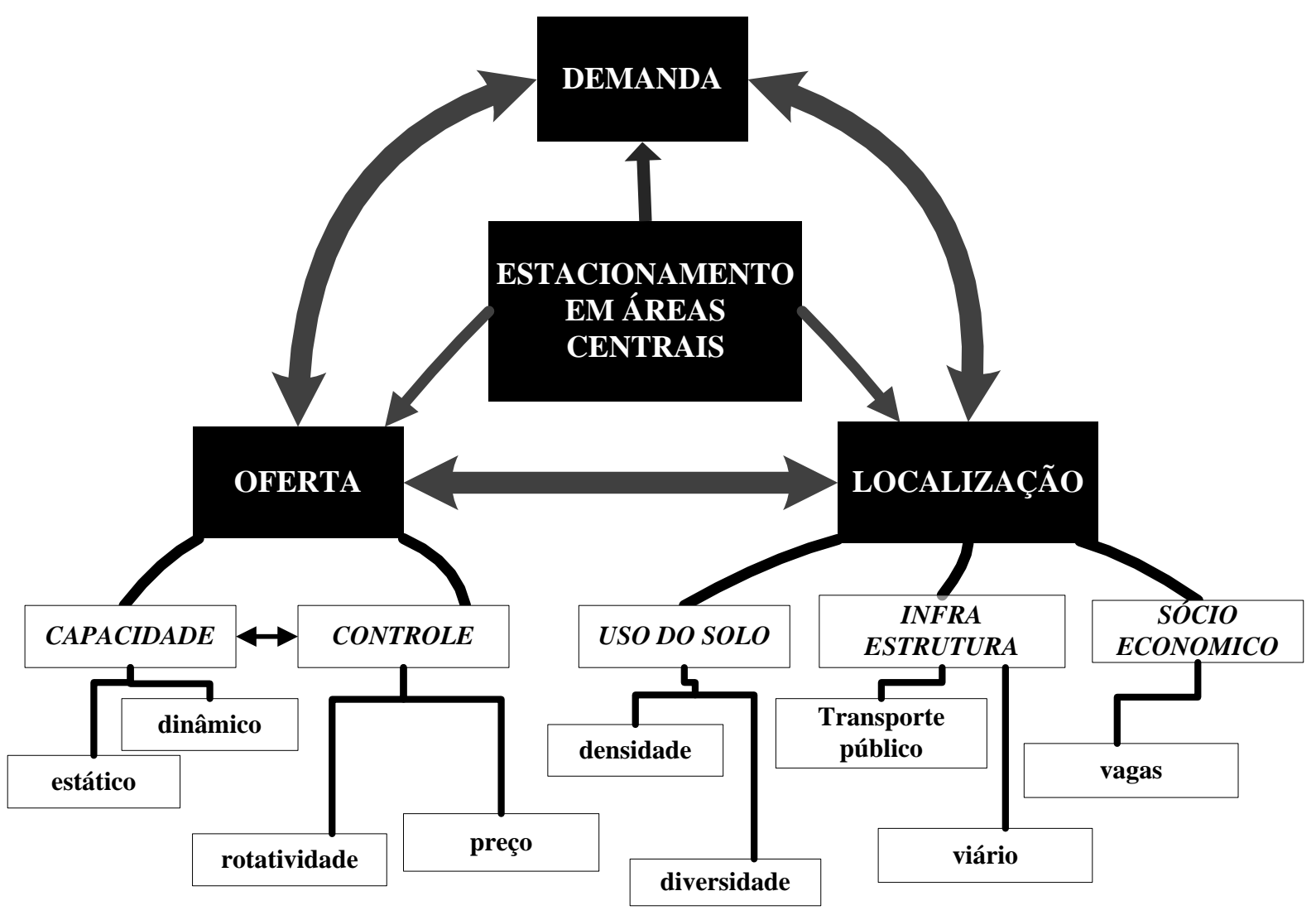

Figura 1 - Fatores que influenciam na geração de viagens de estacionamentos 
Como se observa, alguns fatores estão relacionados às características do estacionamento, como a capacidade e a forma de controle, enquanto outros estão relacionados ao ambiente construído, como o uso do solo, a densidade; à infraestrutura urbana, como a capacidade do sistema viário e de transportes e a acessibilidade ao estacionamento; ou socioeconômicos, como a renda dos usuários, a vitalidade econômica ou a intensidade da atividade econômica.

Nesse contexto, e levando em conta o objetivo desse artigo, cujo foco é a modelagem da geração de viagens dos estacionamentos, esta pesquisa destaca os seguintes fatores intervenientes:

- Localização - é um fator relevante, pois os estacionamentos localizados nas áreas centrais, onde ocorre maior concentração de atividades comerciais, de serviços ou institucionais, tendem a ter maior taxa de geração de viagens;

- Porte - o número de vagas é a variável independente que tem maior influência sobre a quantidade de viagens geradas e, normalmente, é usada nos modelos para determinação das equações de regressão e taxas de geração de viagens;

- Política de Preços - estacionamentos localizados em áreas centrais tendem a cobrar maior preço e ter tabelas progressivas, o que induz à maior rotatividade, enquanto os localizados na periferia da área central tendem a adotar variadas políticas de preço, como a cobrança mensal, que lhes garante maior rentabilidade e induz ao uso por períodos mais longos;

- Dispositivos de controle - podem ser manuais ou automáticos, que dão maior agilidade no acesso e confiabilidade ao controle;

- Tipo de operação - rotativos, quando a cobrança é feita por hora ou fração; mensalistas, quando a cobrança é mensal; ou mistos, quando coexistem os dois tipos;

- Tempo de permanência - trata-se de variável dependente dos demais fatores que, teoricamente, deve ser correlacionada à taxa de geração de viagens;

- Taxa de ocupação média - outra variável dependente, também correlacionada à geração de viagens, que indica a maior ou menor disponibilidade de vagas no período considerado. 


\section{O caso de Niterói}

Localizada na Região Metropolitana do Rio de Janeiro, a cidade de Niterói, com população residente de 487.562 habitantes (IBGE, 2010), é polo da chamada Região Leste Metropolitana, que inclui os municípios situados a leste da Baía de Guanabara: São Gonçalo, Maricá, Itaboraí, Tanguá, Magé e Guapimirim, que somam população de aproximadamente 2,1 milhões de habitantes (IBGE, 2010).

O Centro de Niterói, que constitui a área de estudo deste trabalho, nos seus cerca de 80 hectares, concentra grande diversidade de usos, incluindo administração pública, universidades, hospitais, bancos e comércio diversificado, além do uso residencial (19.698 habitantes). Localizam-se no Centro importantes terminais de transporte, como o Terminal Hidroviário da Praça Araribóia, base da ligação marítima com o Rio de Janeiro, por onde circulam diariamente 100.000 pessoas; o Terminal João Goulart, rodoviário metropolitano, por onde circulam diariamente 350.000 pessoas; e a Rodoviária Roberto Silveira, que concentra as linhas intermunicipais de longo curso.

Estes dados demonstram a vitalidade da área central de Niterói como centro comercial e de serviços, o que atrai grande número de viagens diariamente, tanto por transporte coletivo quanto por automóveis. As viagens de carro geram demanda por vagas que é suprida por estacionamentos públicos ou privados. Estima-se que existem cerca 10.000 vagas no Centro de Niterói, o que corresponde a menos da metade considerando padrões observados em centros de cidades americanas: 2,4 vagas por 1000 pés quadrados (TRB, 2003; ITE, 2008). Esta quantidade de vagas, de forma aproximada, pode ser assim dividida: 2.000 vagas públicas, de rua, das quais cerca de 500 são cativas, reservadas à instituições públicas, pontos de táxi, idosos ou portadores de deficiência física; e 1500 rotativas, exploradas em regime de concessão por empresa privada. Os estacionamentos privados de uso público, voltados para exploração comercial, que são objeto deste estudo, respondem por cerca de 3.000 vagas. Existem, ainda, os estacionamentos vinculados a alguma atividade comercial, como Supermercados ou Shopping Centers, que somam, aproximadamente, 5.000 vagas. Nestes números não estão computados os estacionamentos de uso restrito, vinculados a edificações residenciais ou comerciais. 
Cada estacionamento estabelece sua própria política de preço e tipo de operação, rotativo ou mensal. Nos Shoppings, a tarifa é rotativa e progressiva. No estacionamento de rua, a tarifa foi definida pelo município por meio do contrato de concessão. O último reajuste ocorreu em 2007, quando a tarifa passou de $\mathrm{R} \$ 1,50$ para $\mathrm{R} \$ 3,00$, por período de três horas. O objetivo da concessão, realizada na década de 1990, foi de aumentar a oferta de vagas. Como contrapartida, pela exploração das vagas de rua, a concessionária deveria construir estacionamentos subterrâneos sob algumas praças ou ruas. Entretanto, apenas um estacionamento foi construído, fruto de questionamento pela comunidade, por políticos de oposição ao governo, pelo Ministério Público e, finalmente, pelo embargo da Justiça.

Ao contrário dos estacionamentos privados, onde a tarifa é progressiva e existe rigoroso controle sobre o tempo de permanência dos veículos, a tarifa do estacionamento na rua, além de substancialmente menor, é pouco controlada. De modo geral, o usuário não é punido quando ultrapassa o tempo de três horas. Por este fato, a procura por estacionamento de rua é muito grande, sendo muito difícil encontrar vagas no horário comercial. Nos estacionamentos privados, assim como nos Shopping Centers, com base em observações locais, a oferta é compatível com a demanda, sendo relativamente fácil encontrar vagas, mesmo nos horários de pico.

Para este trabalho, foram pesquisados 29 estacionamentos, no período de 6:00h às 20:00 horas. Esta amostra, que soma 1704 vagas, representa cerca de $60 \%$ do universo em estudo e por meio de sua análise pode-se conhecer a demanda de viagens e o uso dessas instalações.

\section{Procedimento proposto}

O procedimento adotado na pesquisa de campo foi o mesmo desenvolvido para o cálculo de geração de viagem em condomínios residenciais (Marcolini, 2011) apresentado no Caderno Técnico da Nittrans (Nittrans, 2011) que, por sua vez, foi baseado em metodologia consagrada, desenvolvida pelo Institute of Transportation Engineers - ITE para pesquisas de geração de viagens (ITE, 2004; ITE, 2012).

Por meio de formulários específicos, foram realizadas contagens do número de viagens e de tempo de uso das vagas, contemplando as seguintes variáveis: 
- Horário de funcionamento;

- Número de vagas mensais e rotativas;

- Tempo de permanência dos veículos;

- Preços.

Após as contagens veiculares, os dados registrados nos estabelecimentos foram totalizados, de maneira a gerar as quantidades de viagens diárias (entradas e saídas), no pico da manhã, no pico da tarde e durante todo o horário pesquisado. Após a totalização, foi escolhido o dia de maior movimento para o cálculo do tempo de permanência, que foi observado por meio da anotação das placas dos automóveis na entrada e na saída. Todos os dados levantados em campo foram tabelados para se determinar as seguintes variáveis:

- Número de viagens geradas, adotando-se a média diária (foram contados cinco dias úteis, de segunda à sexta-feira);

- Taxas de geração de viagens, adotando-se como variável independente o número de vagas. Considera-se como viagens geradas a soma das viagens atraídas (aquelas que entram no estacionamento) com as viagens produzidas (aquelas que saem). Para cada subárea, foram calculadas as médias ponderadas, de acordo com a metodologia recomendada pelo ITE;

- Porte do estacionamento, definido pelo total de vagas (rotativas + mensais);

- Percentagem de vagas rotativas, considerando-se as vagas rotativas em relação ao total de vagas;

- Preço, considerando-se, para efeito de comparação, o preço cobrado pela primeira hora de utilização;

- Tempo médio de permanência, considerando-se o dia de maior movimento de cada estacionamento;

- Taxa média de ocupação, calculada pelo somatório do tempo de permanência de todos os veículos, multiplicado por 100 e dividido pelo número de vagas multiplicado pelo tempo de operação do estacionamento no período pesquisado, como mostra a Equação 1. A taxa média de ocupação, expressa em porcentagem, representa o quanto todas as vagas ficaram ocupadas durante o tempo pesquisado. 


$$
T O=\frac{\sum \text { Tempo de permanencia }}{\text { NVx Tempo de pesquisa }} \times 100
$$

\subsection{Delimitação da área do estudo}

As Figuras de 2 a 5 mostram a localização de cada estacionamento, assim como a divisão do Centro de Niterói em três subáreas, que apresentam diferentes características quanto ao uso do solo e a intensidade da atividade comercial e de serviços.

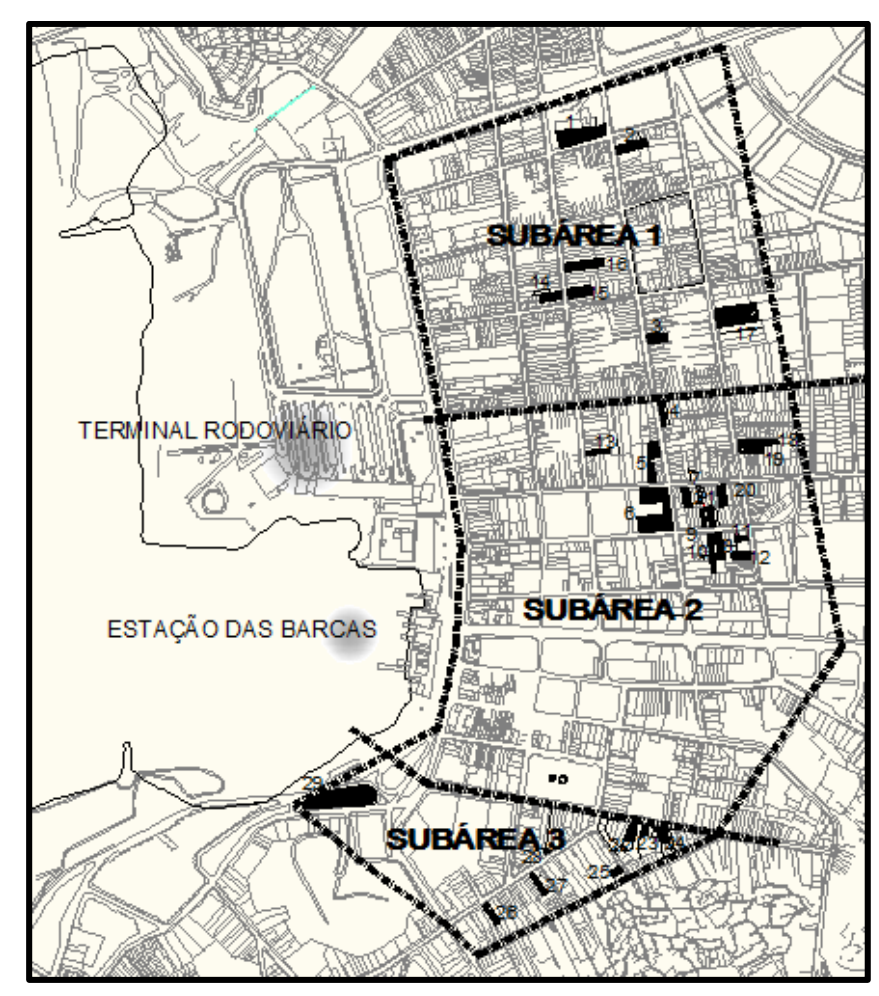

Figura 2 - Mapa da área central e suas subáreas

A área considerada no estudo engloba o centro comercial de Niterói, um polígono limitado pela Avenida Visconde do Rio Branco; pela Avenida Feliciano Sodré (limite com o bairro da Ponta D'Areia), por uma linha que passa pelo fundo dos lotes da Rua Visconde de Sepetiba até a Praça da República; daí por uma linha na direção sudoeste perpendicular às ruas Dr. Celestino e Moacyr Padilha até o limite com o bairro do Morro do Estado; e por dois segmentos de reta até o ponto inicial na Av. Visconde do Rio Branco. Este polígono não engloba todo o bairro Centro, deixando de fora duas subáreas: uma delas, entre a Rua Visconde de Sepetiba e as avenidas Jansen de Melo e Marques do Paraná, apresenta menor atividade comercial; a outra, constituída pelo aterro onde está o Caminho Niemeyer e o 
Terminal João Goulart, que, exceto pelo Terminal Rodoviário, encontra-se praticamente desocupada.

Contudo, mesmo a área considerada no estudo não é homogênea, apresentando diferenças com relação à intensidade da atividade comercial. Por isso, o polígono objeto deste estudo foi dividido em três subáreas: o núcleo Central é a que concentra maior atividade comercial (subárea 2); as duas outras subáreas (1 e 3) podem ser consideradas como periféricas ao centro comercial principal.

A subárea 1 localiza-se ao norte da Área Central e concentra o comércio popular e atividade comercial e de serviços de menor porte. Localiza-se nessa subárea o Prédio da Rodoviária Roberto Silveira, que abriga, além do terminal rodoviário, instalações da administração pública municipal e estadual. Neste trabalho receberá a denominação de "Subárea Rodoviária”.

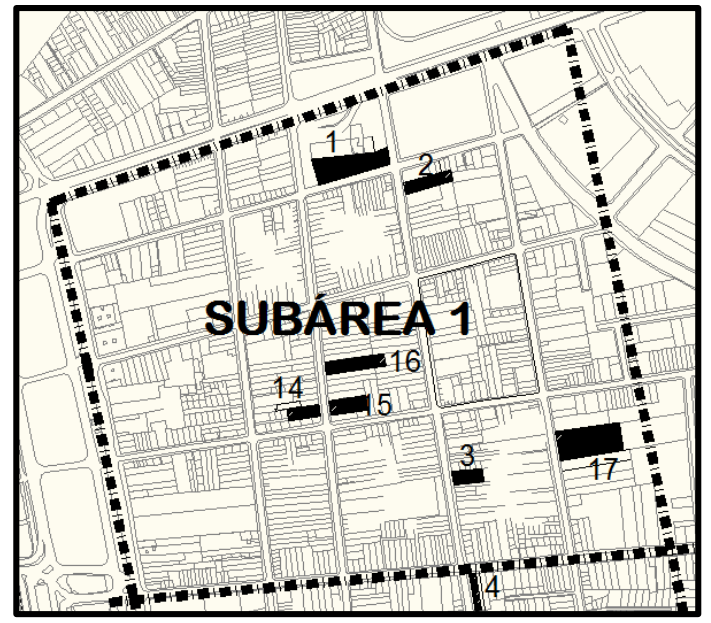

Figura 3 - Localização dos estacionamentos da subárea 1 - Rodoviária

A subárea 2 é a que concentra maior atividade comercial, de serviços e institucional. Nessa subárea estão localizados a Prefeitura, o Fórum, as principais agências bancárias, muitos escritórios e comércio diversificado. Mais valorizada comercialmente, pode ser considerada como o centro comercial da cidade e será denominada como "Núcleo Central”. 


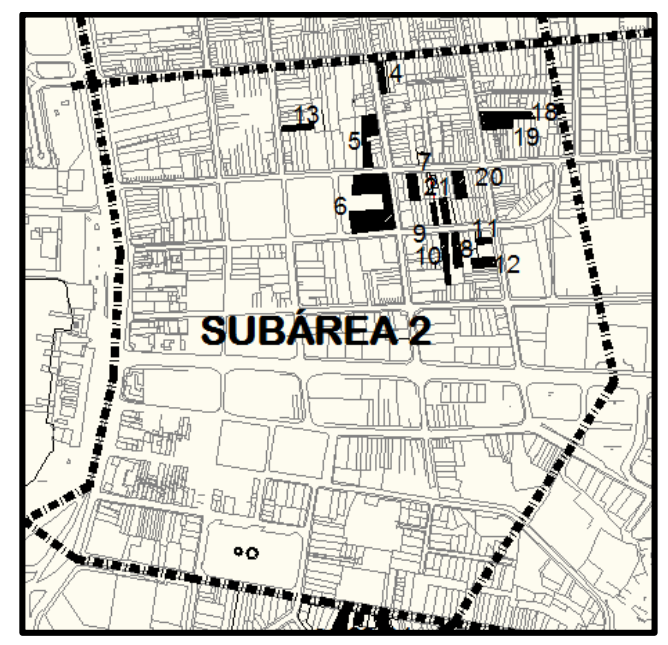

Figura 4 - Localização dos estacionamentos da subárea 2 - Núcleo Central

A subárea 3 fica ao sul da Área Central, limitada por uma grande praça que é popularmente conhecida como Rink, em local de menor valor comercial, entre o Morro do Estado e a Estação das Barcas. A pequena distância em relação ao Núcleo Central, contudo, a torna bastante atrativa para a localização de estacionamentos. Essa área conta, ainda, com a proximidade da Estação das Barcas e do Plaza Shopping, principal polo comercial da cidade, que conta com grande estacionamento, não incluído nesta pesquisa. Será chamada neste trabalho "Subárea Rink".

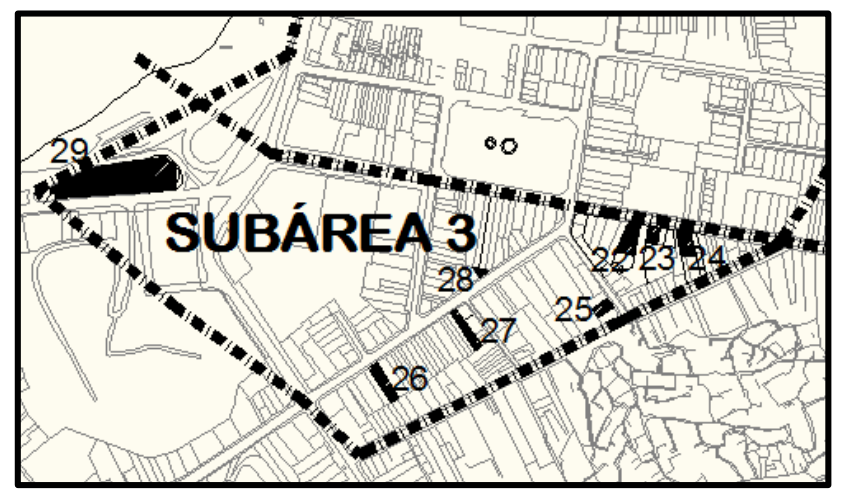

Figura 5 - Localização dos estacionamentos da subárea 3 - Rink 


\subsection{Relações Estabelecidas}

O número de vagas foi definido como a principal variável independente, ou explicativa, a ser correlacionada com o número de viagens geradas, variável dependente, por meio da análise de regressão, bem como calculadas as taxas de geração de viagens para cada estacionamento, que foram relacionadas às seguintes variáveis: a porcentagem de vagas rotativas sobre o total de vagas; o tempo médio de permanência dos veículos nas vagas; a taxa de ocupação média; o porte, definido pelo número de vagas de cada estacionamento; e o preço da primeira hora.

Para cada variável foi calculada a média, o desvio padrão e a média ponderada, cujos dados foram organizados em tabelas referentes a cada uma das três subáreas e para todos os estacionamentos da área central de Niterói; bem como uma síntese contemplando as 3 subáreas.

A seguir, foram traçados os diagramas de dispersão do número de vagas relacionado ao número de viagens, e definidas equações lineares de regressão simples para cada subárea e para a área total. A verificação da aderência foi feita pelo cálculo do coeficiente de determinação $\mathrm{R}^{2}$.

Além disso, foram traçados diagramas de dispersão; definidas as respectivas equações de regressão simples; e calculados os coeficientes de determinação $\mathrm{R}^{2}$ para as relações entre as taxas de geração de viagens e cada uma das variáveis intervenientes que foram selecionadas nessa pesquisa, contemplando todo o conjunto de estacionamentos.

\section{Apresentação dos resultados}

\subsection{Tabelas}

A seguir, são apresentados os resultados obtidos para cada subárea (Tabelas 1, 2 e 3); para a área total (Tabela 4); e o resultado consolidado das 3 subáreas e da área total (Tabela 5). Dos 29 estacionamentos pesquisados, 4 foram desconsiderados por terem apresentado inconsistência nos resultados, restando portanto 25 estacionamentos, que foram agrupados por subárea: 6 na subárea 1- Rodoviária; 11 na subárea 2- Núcleo Central; e 8 na subárea 3 - Rink. 
A primeira coluna apresenta o número de identificação de cada estacionamento. A coluna 2, o porte de cada instalação (número total de vagas); e a terceira coluna, o número de vagas rotativas. A quarta coluna apresenta o total de viagens realizadas, considerando-se a média da semana. As demais colunas apresentam as seguintes variáveis: taxa de geração de viagens; porcentagem de vagas rotativas; preço da primeira hora; tempo médio de permanência dos veículos nas vagas; e a taxa média de ocupação. Para a variável "preço", foi escolhido o preço cobrado pela primeira hora. Todavia, a política de preço adotada pelos estabelecimentos varia muito. Alguns estacionamentos adotam uma tabela altamente progressiva, a partir da primeira meia hora; enquanto em outros, esta progressão é menor. $\mathrm{O}$ valor do aluguel mensal também varia muito: desde o mínimo de $\mathrm{R} \$ 150,00$ até $\mathrm{R} \$ 350,00$, tendo como preço médio $\mathrm{R} \$ 220,00$.

Tabela 1 - Subárea 1 - Rodoviária - dados de 6 estacionamentos

\begin{tabular}{ccccccccc}
\hline \multirow{2}{*}{ Posto } & $\begin{array}{c}\text { Vagas } \\
\text { Totais }\end{array}$ & $\begin{array}{c}\text { Vagas } \\
\text { Rotativas }\end{array}$ & \multirow{2}{*}{ Viagens } & $\begin{array}{c}\text { Taxa } \\
\text { Viagem/Vaga }\end{array}$ & $\begin{array}{c}\text { Rotativas } \\
\%\end{array}$ & $\begin{array}{c}\text { Preço 1a. } \\
\text { Hora - R } \$\end{array}$ & $\begin{array}{c}\text { Tempo } \\
\text { Médio }\end{array}$ & $\begin{array}{c}\text { Taxa } \\
\text { Ocupação \% }\end{array}$ \\
\hline 15 & 20 & 3 & 90 & 4,50 & 15 & 4,00 & $3: 38$ & 49 \\
\hline 14 & 28 & 11 & 54 & 1,93 & 39 & 3,00 & $3: 16$ & 18 \\
\hline 3 & 32 & 16 & 184 & 5,75 & 50 & 6,00 & $2: 15$ & 44 \\
\hline 16 & 42 & 12 & 85 & 2,02 & 29 & 4,00 & $4: 59$ & 27 \\
\hline 2 & 44 & 8 & 98 & 2,23 & 18 & 6,00 & $3: 43$ & 17 \\
\hline 17 & 256 & 16 & 361 & 1,41 & 6 & 6,00 & $4: 46$ & 15 \\
\hline Desvio padrão & 91,39 & 4,98 & 114,27 & 1,73 & 16,36 & 1,33 & 0,04 & 14,75 \\
\hline Total & 422 & 66 & 872 & & & & & \\
\hline Média & 70,33 & 11,00 & 145,33 & 2,97 & 26,17 & 4,83 & $3: 46$ & 28,33 \\
\hline Média ponderada & & & $\mathbf{2 , 0 7}$ & $\mathbf{1 5 , 4 9}$ & $\mathbf{5 , 5 1}$ & $\mathbf{4 : 2 0}$ & $\mathbf{2 0 , 4 1}$ \\
\hline
\end{tabular}

Tabela 2 - Subárea 2 - Núcleo Central - dados de 11 estacionamentos

\begin{tabular}{ccccccccc}
\hline \multirow{2}{*}{ Posto } & $\begin{array}{c}\text { Vagas } \\
\text { Totais }\end{array}$ & $\begin{array}{c}\text { Vagas } \\
\text { Rotativas }\end{array}$ & Viagens & $\begin{array}{c}\text { Taxa } \\
\text { Viagem/Vaga }\end{array}$ & $\begin{array}{c}\text { Rotativas } \\
\%\end{array}$ & $\begin{array}{c}\text { Preço 1a. } \\
\text { Hora R\$ }\end{array}$ & $\begin{array}{c}\text { Tempo } \\
\text { Médio }\end{array}$ & $\begin{array}{c}\text { Taxa } \\
\text { Ocupação \% }\end{array}$ \\
\hline 9 & 15 & 5 & 58 & 3,87 & 33 & 4,00 & $4: 19$ & 71 \\
\hline 20 & 20 & 14 & 103 & 5,15 & 70 & & $2: 32$ & 58 \\
\hline 19 & 20 & 0 & 35 & 1,75 & 38 & & $5: 32$ & 22 \\
\hline 7 & 22 & 22 & 161 & 7,32 & 100 & 4,00 & $2: 31$ & 48 \\
\hline 21 & 23 & 23 & 168 & 7,30 & 100 & 4,00 & $2: 47$ & 64 \\
\hline 8 & 23 & 23 & 115 & 5,00 & 100 & 4,00 & $4: 33$ & 62 \\
\hline 11 & 30 & 21 & 141 & 4,70 & 70 & 6,00 & $2: 06$ & 47 \\
\hline 12 & 50 & 20 & 304 & 6,08 & 40 & 8,00 & $3: 33$ & 71 \\
\hline 18 & 64 & 30 & 136 & 2,13 & 47 & 5,00 & $4: 17$ & 22 \\
\hline 13 & 80 & 40 & 175 & 2,19 & 50 & 6,00 & $5: 01$ & 30 \\
\hline 10 & 144 & 19 & 273 & 1,90 & 13 & 3,00 & $5: 33$ & 35 \\
\hline Total & 491 & 217 & 1669 & & & & & \\
\hline Desvio Padrão & 39,09 & 10,88 & 80,80 & 2,11 & 30,15 & 1,54 & 0,05 & 18,59 \\
\hline Média & 44,64 & 19,73 & 151,73 & 4,31 & 60,09 & 4,89 & $3: 53$ & 48,18 \\
\hline Média Ponderada & & & $\mathbf{3 , 4 0}$ & $\mathbf{4 4 , 2 0}$ & $\mathbf{4 , 7 5}$ & $\mathbf{4 : 2 4}$ & $\mathbf{4 1 , 6 0}$ \\
\hline
\end{tabular}


Tabela 3 - Subárea 3 - Rink - dados de 8 estacionamentos

\begin{tabular}{ccccccccc}
\hline \multirow{2}{*}{ Posto } & $\begin{array}{c}\text { Vagas } \\
\text { Totais }\end{array}$ & $\begin{array}{c}\text { Vagas } \\
\text { Rotativas }\end{array}$ & Viagens & $\begin{array}{c}\text { Taxa } \\
\text { Viagem/Vaga }\end{array}$ & $\begin{array}{c}\text { Rotativas } \\
\%\end{array}$ & $\begin{array}{c}\text { Preço 1a. } \\
\text { Hora R } \$\end{array}$ & $\begin{array}{c}\text { Tempo } \\
\text { Médio }\end{array}$ & $\begin{array}{c}\text { Taxa } \\
\text { Ocupação \% }\end{array}$ \\
\hline 28 & 12 & 4 & 35 & 2,92 & 33 & 5,00 & $4: 33$ & 62 \\
\hline 24 & 24 & 12 & 64 & 2,67 & 50 & & $6: 03$ & 57 \\
\hline 25 & 25 & 0 & 54 & 2,16 & 0 & 3,00 & $8: 54$ & 23 \\
\hline 26 & 35 & 9 & 83 & 2,37 & 26 & 7,00 & $3: 43$ & 24 \\
\hline 22 & 80 & 50 & 227 & 2,84 & 63 & 4,00 & $2: 36$ & 22 \\
\hline 23 & 80 & 50 & 154 & 1,93 & 63 & 4,00 & $3: 29$ & 20 \\
\hline 27 & 100 & 50 & 302 & 3,02 & 50 & 6,00 & $3: 59$ & 41 \\
\hline 29 & 435 & 215 & 967 & 2,22 & 49 & 3,50 & $4: 08$ & 16 \\
\hline Total & 791 & 390 & 1886 & & & & & \\
\hline Desvio Padrão & 139,58 & 70,66 & 309,85 & 0,40 & 21,20 & 1,44 & 0,08 & 18 \\
\hline Média & 98,88 & 48,75 & 235,75 & 2,52 & 41,75 & 4,64 & $4: 40$ & 33 \\
\hline Média poderada & & & & $\mathbf{2 , 3 8}$ & $\mathbf{4 9 , 3 0}$ & $\mathbf{4 , 1 0}$ & $\mathbf{4 : 0 5}$ & $\mathbf{2 3}$ \\
\hline
\end{tabular}

Tabela 4 - Total detalhado - Centro - dados de 25 estacionamentos

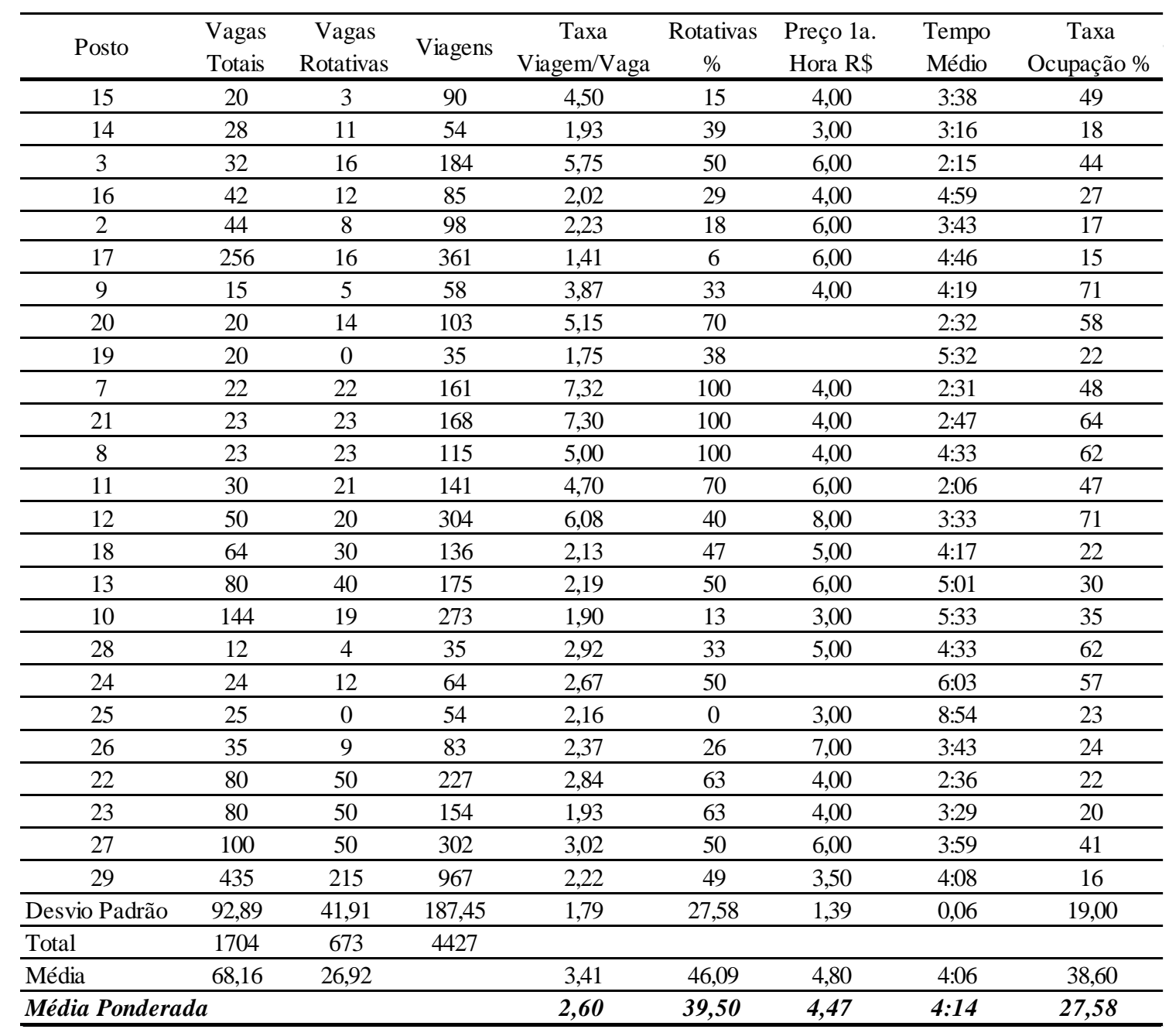


Na Tabela 5, que apresenta o resumo consolidado, considerou-se para cada variável a média ponderada obtida nas tabelas anteriores. Também foram incluídas as equações de regressão e os coeficientes de determinação $\left(\mathrm{R}^{2}\right)$ encontrados em cada subárea e para todo o Centro de Niterói, cujos gráficos de dispersão serão apresentados na seção 4.2.

Tabela 5- Área total consolidado - Centro - Dados de 25 estacionamentos

\begin{tabular}{|c|c|c|c|c|c|c|c|c|}
\hline $\begin{array}{l}\text { Subárea (Número } \\
\text { de Estudos) }\end{array}$ & $\begin{array}{l}\text { Vagas } \\
\text { Totais }\end{array}$ & Viagens & $\begin{array}{c}\text { Taxa } \\
\text { Viagem/Vaga }\end{array}$ & $\begin{array}{c}\text { Rotativas } \\
\%\end{array}$ & $\begin{array}{l}\text { Preço 1a. } \\
\text { Hora - R\$ }\end{array}$ & $\begin{array}{l}\text { Tempo } \\
\text { Médio }\end{array}$ & $\begin{array}{c}\text { Taxa } \\
\text { Ocupação \% }\end{array}$ & Equação $\left(R^{2}\right)$ \\
\hline Rodoviária (6) & 422 & 872 & 2,07 & 15,49 & 5,51 & $4: 20$ & 20,41 & $\begin{array}{c}\mathrm{y}=1,1533 \mathrm{x}+64,215 \\
\mathrm{R}^{2}=0,8509\end{array}$ \\
\hline Núcleo Central (11) & 491 & 1669 & 3,40 & 44,20 & 4,75 & $4: 24$ & 41,60 & $\begin{array}{c}\mathrm{y}=1,3498 \mathrm{x}+91,476 \\
\mathrm{R}^{2}=0,4265\end{array}$ \\
\hline Rink (8) & 791 & 1886 & 2,38 & 49,30 & 4,10 & 4:05 & 23 & $\begin{array}{c}\mathrm{y}=2,2074 \mathrm{x}+17,492 \\
\mathrm{R}^{2}=0.9889\end{array}$ \\
\hline Total & 1704 & 4427 & & & & & & \\
\hline Desvio Padrão & 148,67 & 402,44 & 0,52 & 13,89 & 0,48 & 0:07 & 8,91 & \\
\hline Média & & & 2,62 & 36,33 & 4,79 & $4: 16$ & 28,23 & \\
\hline Média Ponderada & & & 2,60 & 39,46 & 4,64 & $4: 14$ & 27,58 & $\begin{array}{c}y=1,8852 x+48,583 \\
R^{2}=0,8728\end{array}$ \\
\hline
\end{tabular}

\subsection{Gráficos}

Os Gráficos de 1 a 4 mostram os diagramas de dispersão da variável dependente "número de viagens", correlacionada à variável independente "número de vagas" para as 3 subáreas e para a área total. Nos diagramas de dispersão de cada subárea e da área total estão ajustadas as retas que representam a regressão linear simples. Além disso, e de forma similar ao adotado pelo ITE (2012), apresentam-se: as respectivas equações; o coeficiente de determinação R²; o valor da média ponderada da taxa de geração de viagens; a taxa média de ocupação; e o coeficiente de variação, ou desvio padrão percentual, da taxa de geração de viagens. 


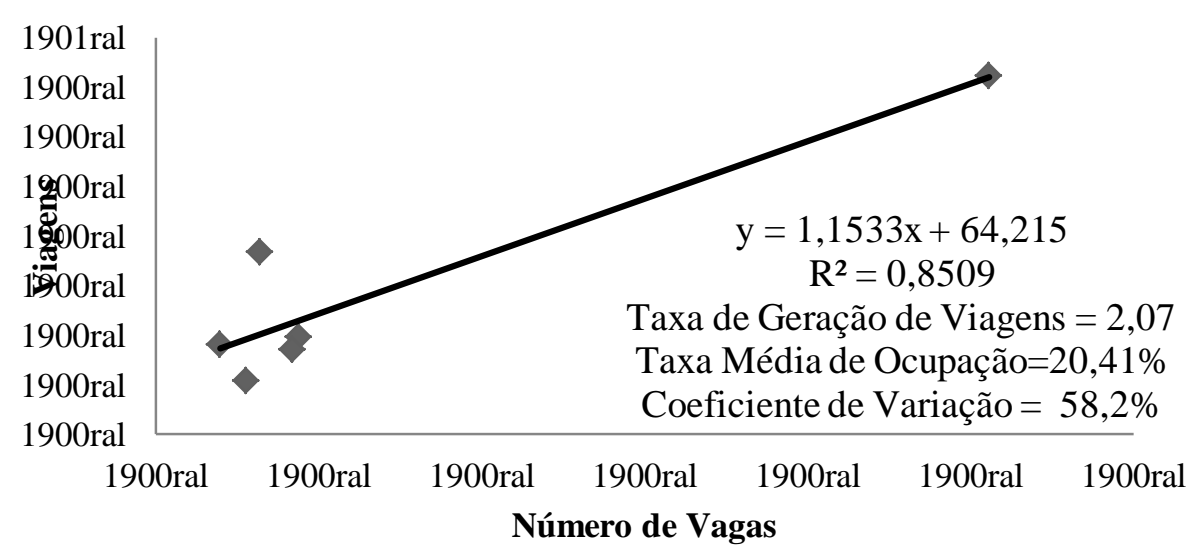

\section{Gráfico 1 - Número de vagas x número de viagens - Subárea 1 - Rodoviária}

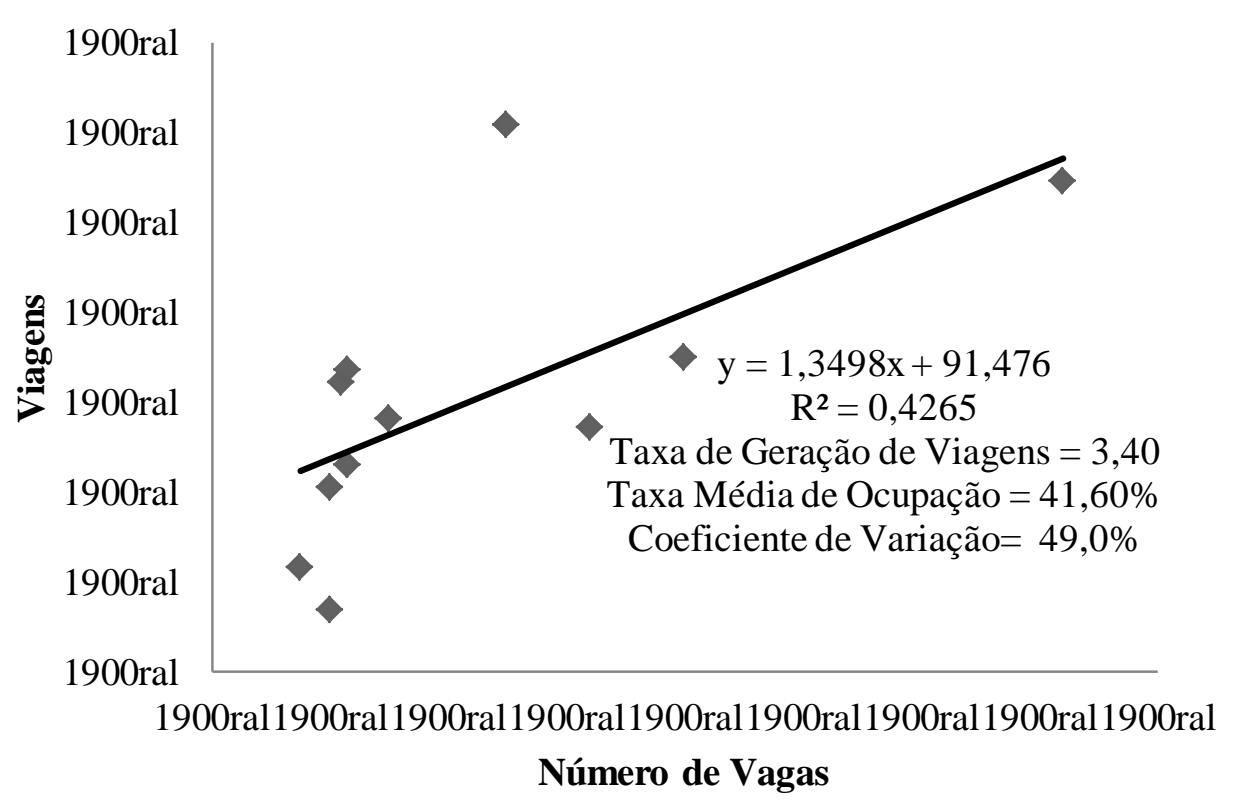

Gráfico 2 - Número de vagas x número de viagens - Subárea 2 - Núcleo Central 


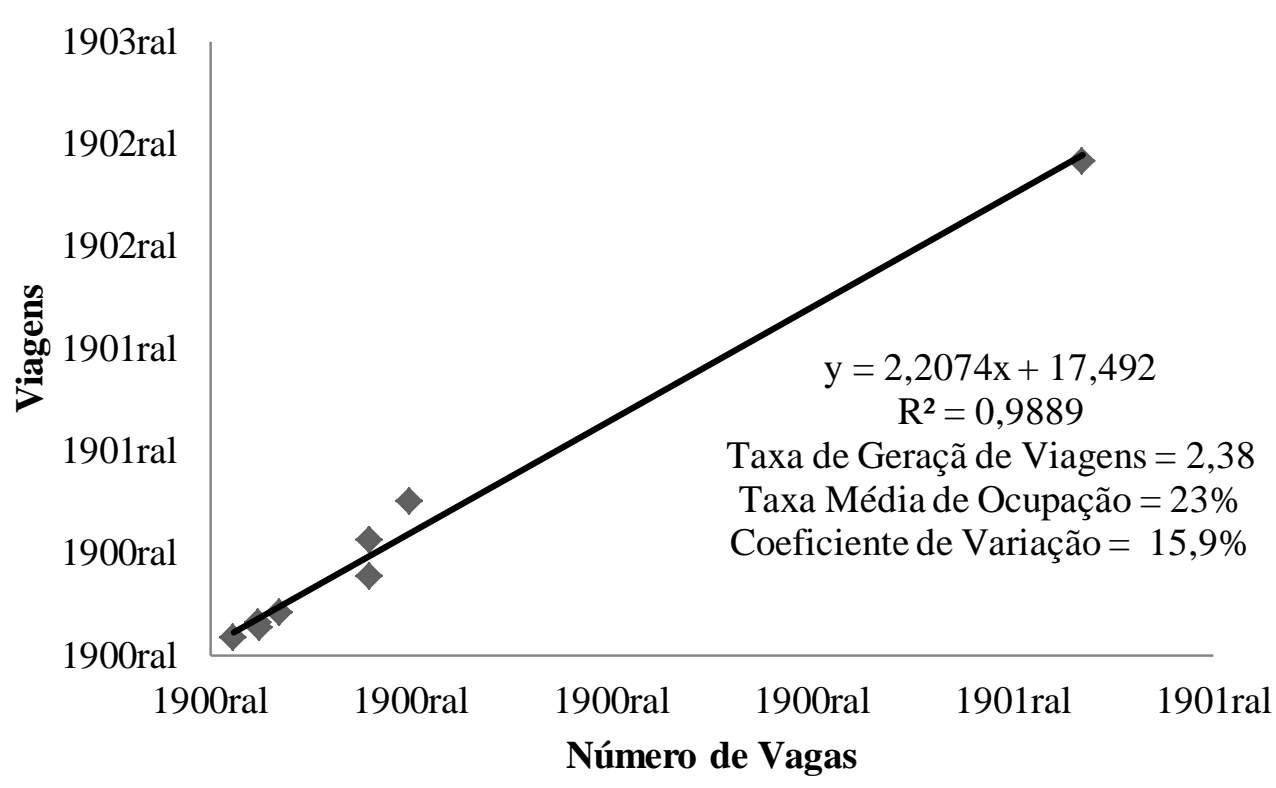

Gráfico 3 - Número de vagas x número de viagens - Subárea 3 - Rink

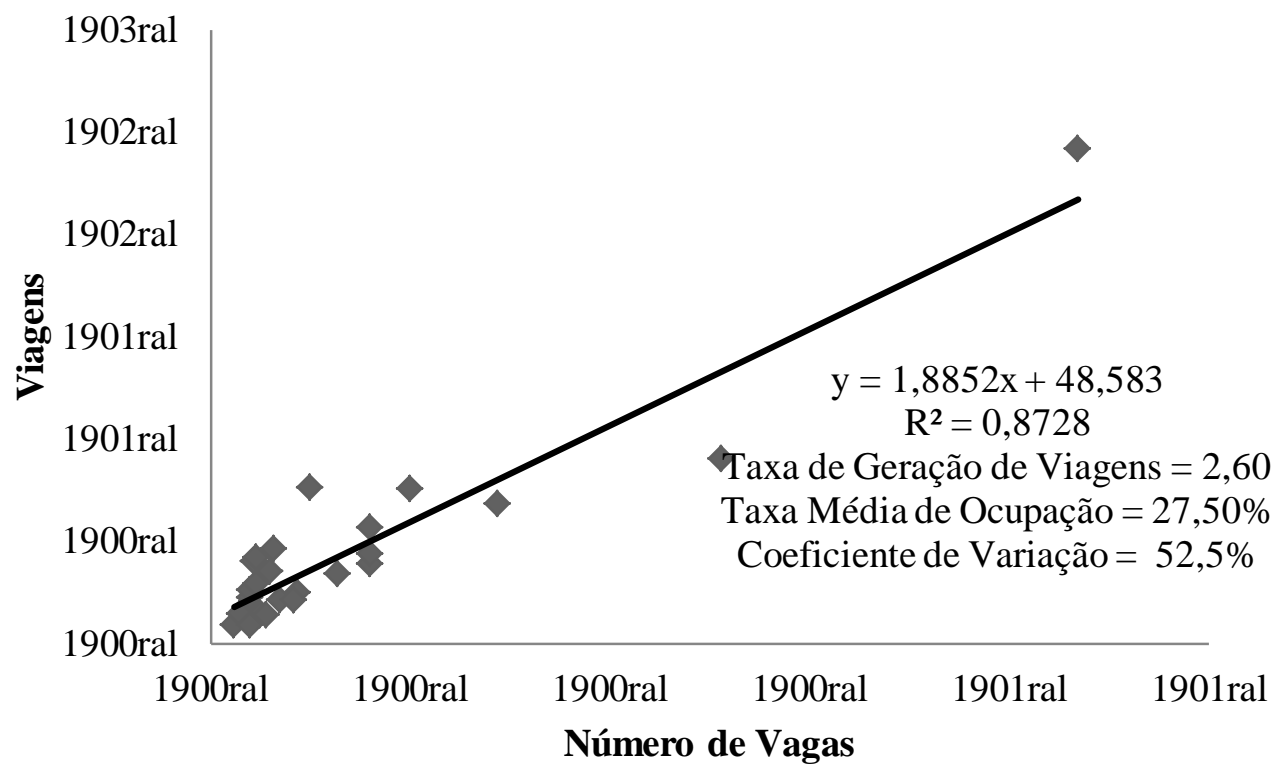

Gráfico 4 - Número de vagas x número de viagens - consolidado de todas as Subáreas 


\section{Análise dos resultados: panorama geral}

Os 25 estacionamentos estudados somam 1704 vagas, apresentando grande variação quanto ao porte: o menor estacionamento tem apenas 12 vagas, enquanto o maior tem 435 vagas. $\mathrm{O}$ quartil inferior da amostra é composto por 6 estacionamentos que têm entre 12 e 22 vagas; os dois quartis intermediários, com 12 estacionamentos, variam de 23 a 64 vagas; e o quartil superior, com 7 estacionamentos, varia de 80 a 435 vagas. O coeficiente de variação é de $136 \%$.

A oferta de vagas rotativas representa apenas 39,50\% do total, somando 673 vagas, enquanto as vagas mensalistas somam 1.031. A preferência dos operadores por ofertar vagas mensais é, à primeira vista, surpreendente, uma vez que as vagas rotativas, aparentemente, deveriam apresentar maior rentabilidade para o estacionamento. Em apenas três pequenos estacionamentos, localizados na subárea Núcleo Central, todas as vagas são rotativas. Por outro lado, dois estacionamentos, também de pequeno porte, oferecem apenas vagas mensais. A maioria dos estabelecimentos $(80 \%)$ oferece, portanto, os dois tipos de operação. Esta opção garante aos proprietários uma renda fixa e uma variável. Evidentemente, conhecendo os hábitos dos usuários mensalistas, algumas dessas vagas podem ser utilizadas como rotativas nos horários de maior demanda. A subárea Rodoviária é a que apresenta menor percentual de vagas rotativas (apenas $15,64 \%$ do total de vagas da subárea), o que pode ser atribuído à menor intensidade do uso comercial e maior participação do uso residencial nessa área; ou, ainda, a uma folga na capacidade diante da demanda, o que justifica a baixa taxa média de ocupação $(20,41 \%)$ e não exige aumento da oferta dinâmica (vagas rotativas).

O preço médio das vagas rotativas era de $\mathrm{R} \$ 4,62$, na época da realização da pesquisa (primeiro semestre de 2012). Observa-se que a subárea Rink, onde existe a maior oferta de vagas rotativas (390, o que representa 49,30\% das vagas da subárea), o preço médio é inferior (R \$ 4,10); e na subárea Núcleo Central é ligeiramente superior (R\$ 4,75). Surpreendentemente, a Área Rodoviária apresenta o maior preço médio para vagas rotativas ( R \$ 5,34). No entanto, nessa subárea, onde o uso residencial compete com o comercial, o tipo de operação predominante é o mensalista e, consequentemente, a menor oferta de vagas rotativas pode justificar o preço maior. 
O tempo médio de permanência nas vagas é de 4:10h, não sendo observada diferença significativa entre as três subáreas, embora a Núcleo Central tenha apresentado resultado ligeiramente superior à média (4:24h). Os valores encontrados superam o que se observa nos Estados Unidos, que, segundo Homburger et al. (2007), varia de 1:20h (cidades menores) a 3:00h (cidades maiores).

A taxa de ocupação média é de $28 \%$, sendo significativamente superior no Núcleo Central (41\%), resultado compatível com a maior demanda por estacionamento, sendo esta área a que apresenta maior atividade comercial e de serviços. Observe-se que a taxa de ocupação média considera todo o período da pesquisa, de 6:00h às 20:00h. Com a abordagem adotada, não foi possível determinar a taxa de ocupação máxima, que, provavelmente, ocorre entre o final da manhã e o início da tarde. Contudo, as taxas de ocupação média são relativamente baixas e, inclusive na Área Central, não é provável que ocorra a lotação máxima dos estacionamentos, mesmo nos horários de maior demanda.

\section{Análise dos resultados: equações e taxas de geração de viagens}

Antes de analisar os resultados, cabe ressaltar que não se encontrou na bibliografia consultada nenhum estudo sobre estacionamentos em área central que tratassem das equações e taxas de geração de viagens. No ITE (2012), foram identificados valores para os estacionamentos do tipo "Park-and-Ride" articulados à linhas de ônibus e às estações de LRT (Light Rail Transit). No primeiro caso, foram 4 estacionamentos pesquisados, com 256 vagas em média, com uma taxa média de 4,50 viagens por vaga (intervalo de 3,90 a 7,06). Enquanto no segundo caso, apenas dois estacionamentos, com 380 vagas em média, com uma taxa média de 2,51 viagens por vaga (intervalo de 1,78 a 3,54$)$.

A partir dessa restrição de referências bibliográficas, e levando em conta os resultados encontrados, verifica-se que, coerente com a baixa taxa de ocupação média e a baixa participação de vagas rotativas, a taxa de geração de viagens observada na área central de Niterói também pode ser considerada baixa (média ponderada de 2,60 viagens por vaga para a área total), com a rotatividade consequentemente pequena. 
Contudo, a taxa varia bastante entre as subáreas e entre os estacionamentos. O desvio padrão é de 1,79 e o coeficiente de variação é de 52,5\%. O intervalo vai de 1,49 viagens/vaga, registrado na subárea Rodoviária a 7,32 viagens/vaga, registrado na subárea Núcleo Central. Um dos estacionamentos pesquisados (Posto 1 - Rodoviária Roberto Silveira) apresentou taxa de 11,76 viagens por vaga, mas foi descartado na análise de consistência, quando se verificou que foram computadas as viagens de táxi feitas a partir de um ponto localizado na entrada do estacionamento.

Como esperado, o Núcleo Central foi a única a apresentar taxa superior a media $(3,40$ viagens/vaga); sendo seguido pela subárea Rink (2,38 viagens/vaga); e pela subárea Rodoviária com a menor taxa (2,07 viagens/vaga), fruto de sua menor atividade comercial.

Para se estimar a geração de viagens, em estudos ou projetos que necessitem desses dados, podem-se utilizar as taxas de geração de viagens ou as equações de regressão. De acordo com os critérios adotados pelo ITE (2008), a equação de regressão deve ser usada quando se tem acima de 20 pontos estudados, ou, para estudos dentro do cluster (parte do diagrama de dispersão onde se acumulam parte significativa dos pontos) quando se tem a partir de 6 pontos e $\mathrm{R}^{2}$ maior ou igual a 0,75 (Andrade e Portugal, 2012). Esta condição é alcançada para as seguintes áreas: Rodoviária (6 estudos e $\mathrm{R}^{2}=0,85$ ); $\operatorname{Rink}\left(8\right.$ estudos e $\mathrm{R}^{2}=0,99$ ); e para a soma das 3 áreas (25 estudos e $\mathrm{R}^{2}=0,87$ ).

Quando essas condições não são alcançadas, como é o caso do Núcleo Central, que tem 11 estudos, mas o $\mathrm{R}^{2}$ é de 0,43 , o ITE recomenda o uso da média ponderada da taxa de geração de viagens, para estudos dentro do cluster, desde que tenha coeficiente de variação menor ou igual a $110 \%$. Essa condição é atendida na Área Núcleo Central que tem média ponderada de 3,40 e coeficiente de variação de $49 \%$.

Investigando os motivos que levaram à maior dispersão dos pontos no gráfico da subárea Núcleo Central, observa-se a influência de dois fatores: o porte e a porcentagem de vagas rotativas. Os três estacionamentos de maior porte estão quase perfeitamente alinhados e apresentam baixas taxas de geração de viagens, enquanto os estacionamentos de menor porte, com exceção do Posto 19, apresentam bastante coesão e altas taxas de geração de viagens. O Posto 19, que apesar de pequeno porte (20 vagas) apresenta baixa taxa de geração de viagens 
e está alinhado com os de maior porte, tem apenas vagas mensalistas (porcentagem de vagas rotativas igual a zero).

A seguir serão verificadas, por meio de diagramas de dispersão, as possíveis relações entre a taxa de geração de viagens e as variáveis que, supostamente, teriam influência sobre as mesmas.

O Gráfico 5 mostra o diagrama de dispersão da Taxa de Geração de Viagens X Porcentagem de Vagas Rotativas. Como se esperava, existe uma relação direta entre as duas variáveis: quanto maior a percentagem de vagas rotativas, maior a taxa de geração de viagens. $\mathrm{O}$ valor de $\mathrm{R}^{2}(0,46)$ mostra que existe razoável aderência entre os pontos, o que confirma a relação.

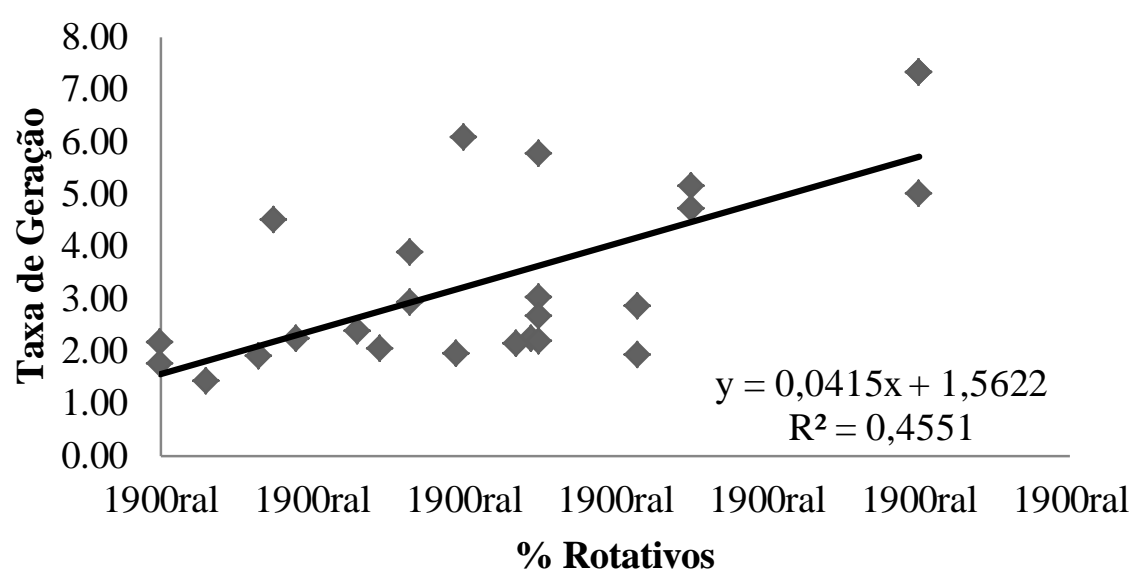

\section{Gráfico 5 - Porcentagem de vagas rotativas $X$ taxa de geração de viagens}

O Gráfico 6 mostra a relação entre a Taxa de Geração de Viagens e o Tempo de permanência, confirmando a relação inversa entre elas: quanto maior o Tempo de Permanência, menor a Taxa de Geração de Viagens. O valor de $\mathrm{R}^{2}(0,297)$ apresenta baixa aderência entre os pontos. 


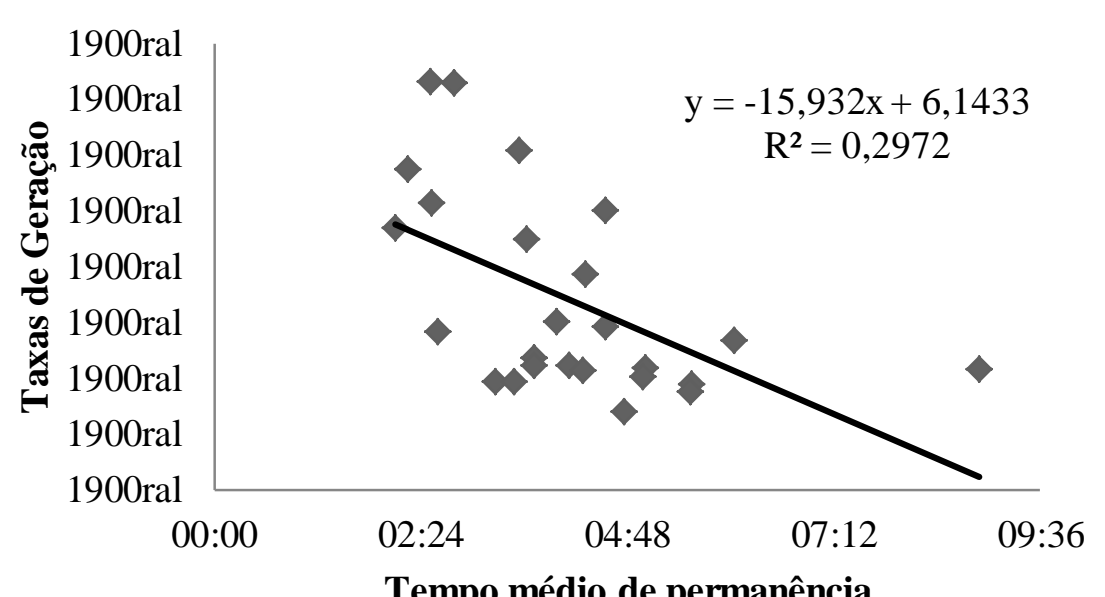

\section{Gráfico 6 - Taxa de geração de viagens $X$ tempo de permanência}

O Gráfico 7 apresenta a relação entre a Taxa de Geração de Viagens e o Preço da Primeira Hora, sendo que o valor de $\mathrm{R}^{2}(0,0234)$ indica ser muito baixa (se alguma) a capacidade de explicação dessa variável Preço sobre a taxa de geração de viagens.

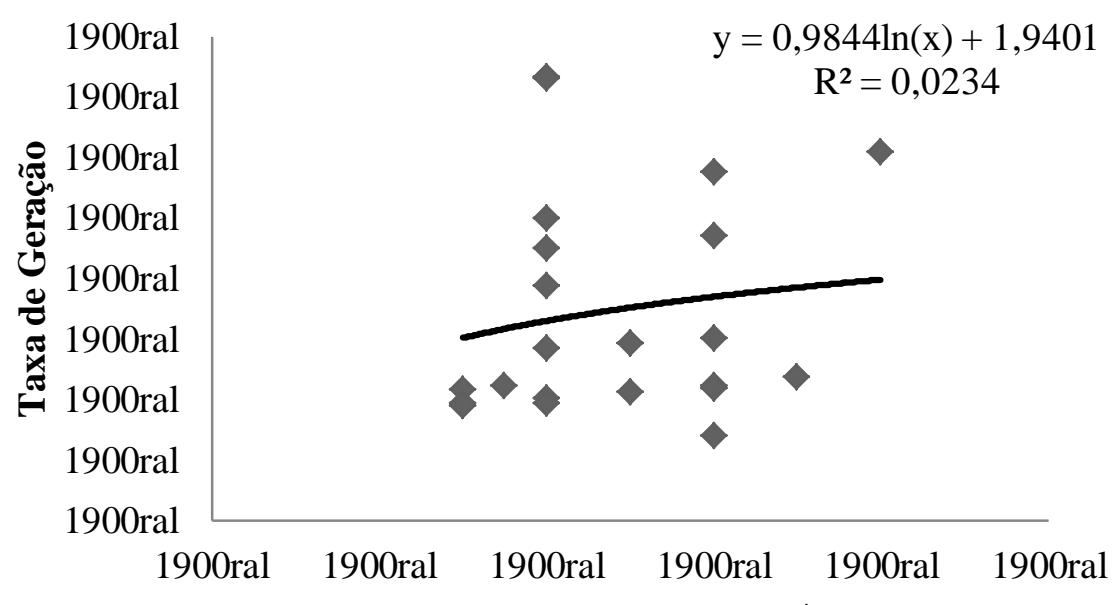

\section{Valor da 1a. Hora - R\$}

\section{Gráfico 7 - Taxa de geração de viagens x preço da primeira hora}

O Gráfico 8 mostra a relação entre a Taxa de Geração de Viagens e a Taxa da Ocupação Média, revelando existir uma relação direta entre as duas variáveis: quanto maior a taxa de ocupação média, maior a taxa de geração de viagens. $O$ valor de $R^{2}(0,539)$ mostra que essa variável apresentou a melhor correlação entre os pontos. 


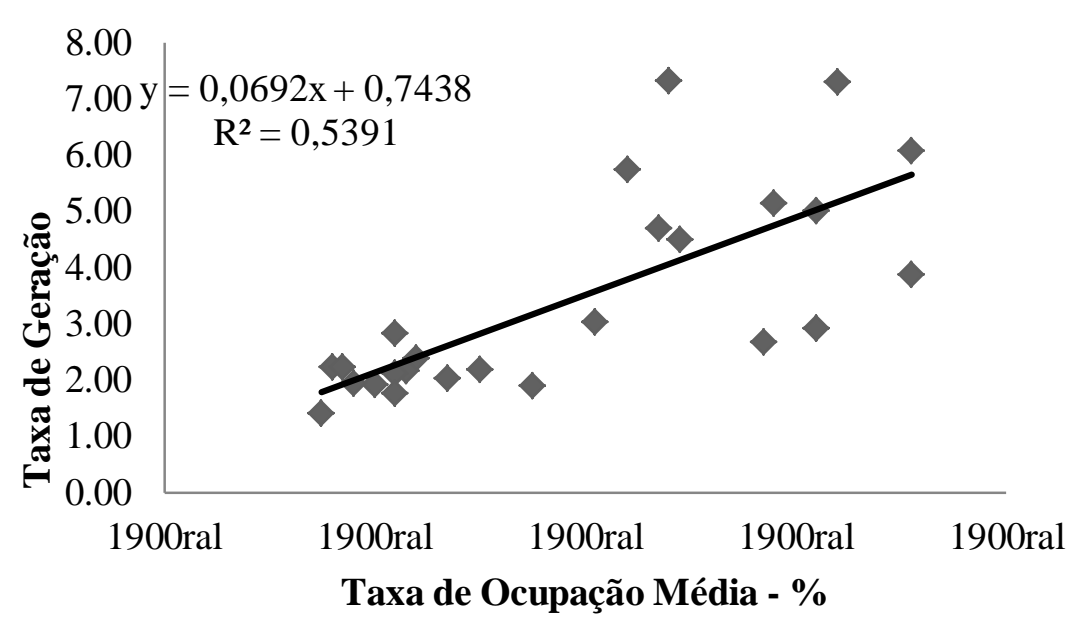

\section{Gráfico 8 - Taxa de geração de viagens x taxa da ocupação média}

O Gráfico 9 mostra a relação entre a Taxa de Geração de Viagens e o Porte do estacionamento. Este gráfico revela que, para os 8 estacionamentos que contam com mais de 60 vagas, ocorre pequena variação nas taxas de geração de viagens (de 1,40 a 3,0), porém, para os estacionamentos menores, observam-se dois grupos: um deles apresentando taxas maiores (de 3,9 a 7,2); enquanto o outro grupo apresenta taxas similares aos com mais de 60 vagas. Dos 9 estacionamentos que compõem o primeiro grupo, 7 estão localizados na subárea Núcleo Central e 2 na subárea Rodoviária. Já no segundo grupo, composto por 8 estacionamentos, 4 estão na subárea Rink; 3 na Rodoviária e apenas 1 no Núcleo Central e todos têm baixo porcentual de vagas rotativas.

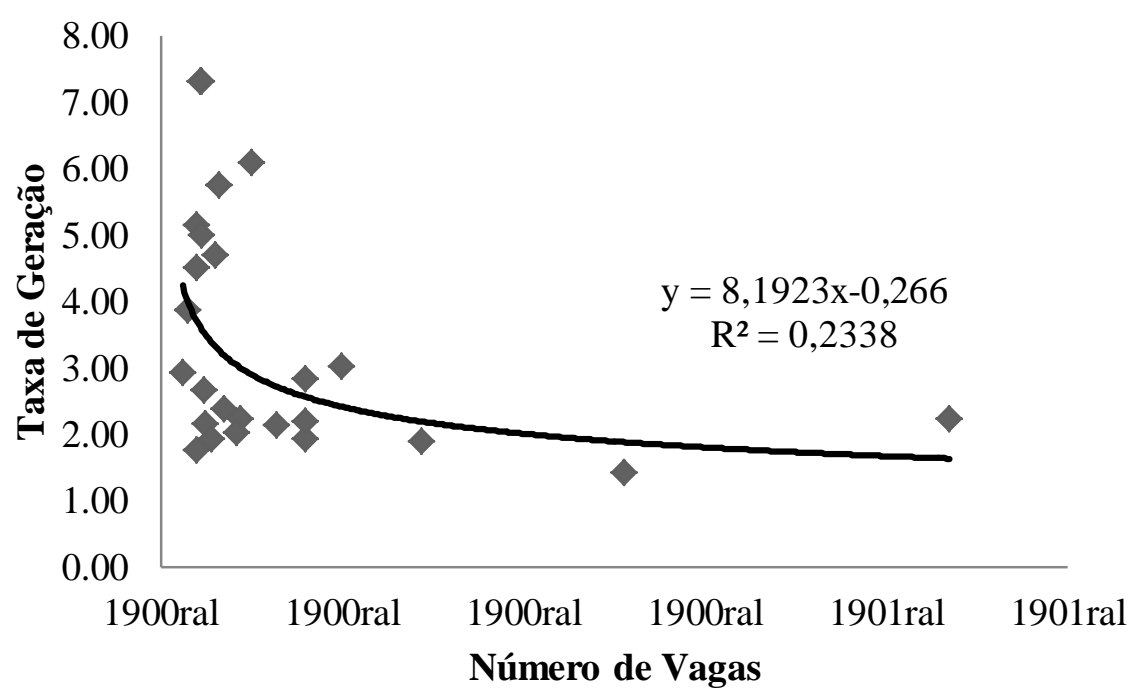

Gráfico 9 - Taxa de geração de viagens $x$ porte do estacionamento 


\section{Conclusão}

No Centro de Niterói, área objeto deste estudo, predominam estacionamentos de pequeno porte, constituídos por lotes de terreno a partir de edificações demolidas, envolvendo, em pelo menos um caso, um prédio com valor histórico, o que alertou a Prefeitura para exercer com maior rigor a fiscalização dessas mudanças de uso do solo. Certamente, o valor comercial desses prédios era baixo e, diante da carência de vagas, muitos proprietários descobriram uma atividade lucrativa, que exige baixo investimento: os estacionamentos.

Estes estacionamentos privados de uso público cumprem importante papel na acessibilidade ao comércio e serviços localizados no centro da cidade, complementando a baixa oferta de estacionamento de rua e equilibrando a concorrência exercida pela excessiva oferta de vagas nos Shopping Centers e Supermercados.

A maioria dos estacionamentos privados adota o tipo misto de operação, oferecendo vagas mensais e rotativas. Esta opção parece estar relacionada com a baixa taxa de ocupação média dos estacionamentos. Provavelmente, os operadores procuram combinar vagas mensais, que garantem uma renda fixa a preços menores, com vagas rotativas, com tabela progressiva de preço, que geram alta rentabilidade por vaga, mas deixam muitas vagas ociosas (baixa taxa de ocupação média).

Evidentemente, a baixa taxa de ocupação média é resultado da significativa diferença de preço entre os estacionamentos de rua, que estão sempre lotados no horário comercial, e os estacionamentos privados, onde é sempre possível encontrar uma vaga, mesmo nos horários de maior demanda. As tabelas de preço variam muito, refletindo as características de cada estacionamento, sendo mais elevadas naqueles localizados em áreas de maior demanda. De modo geral, para um tempo de permanência médio de 4 horas, o usuário gasta acima de $\mathrm{R} \$$ 10,00 nos estacionamentos privados, enquanto na rua, gastaria $\mathrm{R} \$ 6,00$ se pagasse por dois períodos, mas, como o controle é precário, normalmente ele paga apenas $\mathrm{R} \$ 3,00$, que corresponde a um período de 3 horas.

Contudo, não foi possível estabelecer uma relação entre as taxas de geração de viagens e o preço da primeira hora cobrado nos estacionamentos privados. Outros fatores, como a localização (Núcleo Central) e o tipo de operação $\left(R^{2}=0,46\right)$, exercem maior influência sobre a taxa de geração de viagens. 
Por outro lado, o estudo mostra que as taxas de geração viagens são influenciadas por outras variáveis. Como era de se esperar, a subárea Núcleo Central apresenta maior taxa de geração de viagens e maior taxa de ocupação média. Este resultado indica que a localização do estacionamento numa área com maior atividade comercial e de serviços gera maior demanda por estacionamento. Contudo, as taxas de ocupação média encontradas, mesmo nessa subárea, são relativamente baixas, indicando que, durante o período pesquisado, 68,4\% das vagas estiveram ociosas.

De acordo com o coeficiente de determinação, a taxa de ocupação média $\left(\mathrm{R}^{2}=0,54\right)$ e o tipo de operação $\left(R^{2}=0,46\right)$ são as que exerceram a maior influência sobre a taxa de geração de viagens, seguidas pelo tempo de permanência $\left(R^{2}=0,30\right)$ e o porte do estacionamento $\left(R^{2}=\right.$ $0,23)$.

As taxas de geração de viagens e equações de regressão encontradas são a principal contribuição deste estudo, não só pela ausência de estudos similares retratando o contexto das áreas centrais das cidades brasileiras, e mesmo internacionais, mas, sobretudo, pela consistência dos resultados alcançados, rigorosamente de acordo com os padrões definidos pelo ITE (2004) para este tipo de pesquisa.

Estas equações e taxas poderão ser utilizadas em outros estudos, especialmente naqueles que precisam estimar impactos no sistema viário de empreendimentos desse tipo. Para estacionamentos localizados em áreas centrais, recomenda-se a utilização da equação de regressão da área total (Gráfico 4), que conta com maior número de pontos pesquisados (25) e apresenta coeficiente de determinação relativamente alto, $\mathrm{R}^{2}=0,87$. Contudo, de acordo com as características do empreendimento, as outras equações e taxas poderão ser utilizadas. Para áreas periféricas ao centro comercial, a equação de regressão da subárea Rink apresenta excelente coeficiente de determinação, $R^{2}=0,99$. Já para pequenos estacionamentos localizados em áreas de grande atividade comercial, deve ser usada a taxa média ponderada da subárea Núcleo Central: 3,40 viagens/ vaga.

Porém, nunca é demais ressaltar as limitações do presente estudo: foram pesquisados apenas 25 estacionamentos privados de uso público. Não foram objeto dessa pesquisa os estacionamentos de rua, rotativos ou gratuitos; nem aqueles vinculados a estabelecimentos comerciais, como Shopping Centers e Supermercados. Com relação a estes, existem pesquisas 
da CET/ SP (2011) que, porém, utilizam como variável independente a área computável e não o número de vagas. Com relação aos estacionamentos de rua, não foram encontrados estudos que estimem a geração de viagens com base na realidade brasileira. Portanto, a realização de novos estudos que aprofundem o conhecimento sobre o tema é de fundamental importância para respaldar ou confrontar os resultados aqui apresentados.

Outro aspecto relevante, que merece maior reflexão e mesmo ser aprofundado em novas pesquisas sobre o tema, é a baixa taxa de ocupação média dos estacionamentos privados, quando comparada com a plena ocupação dos estacionamentos de rua. Uma alternativa é considerar a minimização do fenômeno do "cruising", na forma do modelo proposto por Arnott e Inci (2005).

O município de Niterói não adota qualquer política de gerenciamento da demanda por meio de restrição ao estacionamento. Ao contrário, adota a abordagem tradicional que busca atender à demanda com preços módicos. Contudo, o gerenciamento da demanda, mesmo não sendo uma política deliberadamente adotada pelo município, acaba, na prática, sendo efetivada pelos agentes privados, que, na busca de maximizar seus resultados financeiros, adotam uma política de preços agressiva, com tabela progressiva, o que impõe uma certa restrição à demanda. Mas, evidentemente, essa política baseada na maximização dos lucros não tem qualquer objetivo relacionado à política de mobilidade. Não visa eliminar o “cruising” e, muito menos, reduzir o uso do automóvel e aumentar a participação do transporte público e dos meios não motorizados.

A adoção de uma política de gerenciamento da demanda nos moldes da adotada em diversas cidades europeias parece ser viável e recomendável, mas, para tanto, o município precisa ter maior controle sobre a oferta de estacionamento na área central, o que não ocorre. Independentemente deste controle, para que a Prefeitura cumpra com o seu papel e consiga conceber e implementar políticas de interesse público, é fundamental que ela invista no conhecimento e em pesquisas, até para aproveitar os recursos disponíveis, inclusive as potencialidades do estacionamento de automóveis para promover uma mobilidade orientada às modalidades mais produtivas socialmente. 


\section{Agradecimentos}

Ao apoio do CNPq e da Rede Ibero-Americana de Estudo em Polos Geradores de Viagens (http://redpgv.coppe.ufrj.br).

\section{Referências}

Andrade, E. P. e Portugal, L. S. (2012) Geração de viagens em PGVs. In: Portugal, L. S. (org) Polos geradores de viagens orientados à qualidade de vida e ambiental. Rio de Janeiro: Editora Interciência, pp. 105-133.

Arnott, R. e Inci, E. (2005) An integrated model of downtown parking and traffic congestion. Paper: Boston College Department of Economics.

Brinco, R. (2006) Transporte urbano e dependência do automóvel. Porto Alegre: Fundação de economia e estatística.

CET/SP - Pereira, G. G. (2011) Modelo de atração de automóveis por Shopping Centers. São Paulo: Companhia de Engenharia de Tráfego.

Denatran - Departamento Nacional de Trânsito (2008) Resolução CONTRAN 302/2008. Disponível em www.denatran.gov.br.

Engel-Yan, J. e Passmore, D. (2010) Assessing alternative approaches to setting parking requirements. ITE Journal, pp. 30-34.

FDOT (2012) Impact of parking supply and demand management on central business district (CBD) traffic congestion, transit performance and sustainable land use. Florida Department of Transportation.

Gonçalves, J. A. M., Portugal, L.S. e Vianna, M.M.B. (2012) Centros e subcentros urbanos: estacionamento e qualidade de vida em Polos geradores de viagens orientados à qualidade de vida e ambiental. Rio de Janeiro: Editora Interciência, pp. 637-669.

Habib, K. M. N., Morency, C. e Trépanier, M. (2012) Integrating parking behaviour in activity-based travel demand modelling: Investigation of the relationship between parking type choice and activity scheduling process. Transportation Research Part A, vol. 46, pp. 154-166.

Homburger, W.S.; Hall, J.W.; Reilly, W.R. e Sullivan, E.C. (2007) Fundamentals of traffic engineering. $16^{\text {th }}$ Edition. Institute of Transportation Studies. University of California, Berkeley. ISSN 0192-5911.

IBGE - Instituto Brasileiro de Geografia e Estatística (2010) Censo Demográfico. Disponível em www.ibge.gov.br.

ITE - Institute of Transportation Engineers (2004) Parking Generation. Washington: ITE, publication n. $034 \mathrm{C}$.

ITE - Institute of Transportation Engineers (2004) Trip generation handbook. Washington: ITE publication $n .028 B$.

ITE - Institute of Transportation Engineers (2008) Transportation planning handbook, 3rd Edition, Washington, DC, EUA.

ITE - Institute of Transportantion Engineers (2012), Trip Generation, 9 th Edition, Publication No. 016G. Washington, DC, EUA.

Kodranksy, M. (2011) Europe's Parking U-Turn: From Accommodation to Regulation, ITDP. 
Niterói (1995) Lei de uso e ocupação do solo. Prefeitura de Niterói. Secretaria Municipal de Urbanismo. Disponível em www.urbanismo.niteroi.gov.rj.br.

NITTRANS - Niterói, Transporte e Trânsito (2011) Caderno Técnico 01 - Geração de viagens: uso residencial. Niterói: Nittrans. Disponível em www.nittrans.niteroi.gov.rj.br.

Marcolini, S. (2011) Geração de viagens em condomínios residenciais. Niterói - Um Estudo de Caso. UFRJ. Programa de Engenharia Urbana - Escola Politécnica.

Pierce, G. e Shoup, D. (2013) Getting the prices right: an evaluation of pricing parking by demand in San Francisco. Journal of the American Planning Association, vol. 79, n. 1, pp. 67-81.

Portugal, L. S. (1990) Método para estabelecimento do número de vagas em áreas centrais: uma análise crítica e algumas proposições. Revista dos Transportes Públicos, n. 50, pp. 37-58.

Portugal, L. S. org. (2012) Polos geradores de viagens orientadas à qualidade de vida e ambiental: modelos e taxas de geração de viagens. Rio de Janeiro: Editora Interciência.

Seco, A. J. M., Gonçalves, J. H. G. e Costa, A. H. P. (2008) Estacionamento, Comissão de Coordenação da Região Norte, Coimbra, Portugal

Shatinawi, I. M. (2010) Abu Dhabi parking rates requirements. ITE Journal, September, pp. 42-45.

Stover, V. G. e Koepke, F. J. (2006) Transportation and land development. $2^{\text {nd }}$ Edition. ITE - Institute of Transportation Engineers. ISBN: 0-935403-68-X. Washington, DC.

TRB (2003) Parking management and supply. TCRP Report 95. Transit Cooperative Research Program. Chapter 18. Transportation Research Board. ISBN 0-309-08763-5. Washington, D.C.

Weinberger, R. (2010) U.S. Parking policies: an overview of management strategies, ITDP. 